\title{
Using Case Studies to Enhance the Critical Thinking Skills of IE Students
}

\section{Dr. Alexandra Chronopoulou, University of Illinois, Urbana-Champaign}

Alexandra Chronopoulou is an Assistant Professor at the University of Illinois at Urbana-Champaign in the Department of Industrial \& Enterprise Systems Engineering. Her main research interests are in the areas of statistical inference for stochastic processes with long memory, stochastic simulation, stochastic modeling and financial engineering. Dr. Chronopoulou received her Master in Computational Finance, and her Ph.D. in Statistics from Purdue University, respectively in 2008 and 2009. Before joining the University of Illinois, she has held a post-doctoral position in INRIA at Nancy (France), and she was an Assistant Professor at the University of California, Santa Barbara, and at the City College of New York (CUNY).

\section{Dr. Kelly J. Cross, University of Illinois, Urbana-Champaign}

Dr. Cross completed her doctoral program in Engineering Education at Virginia Tech in 2015 and is currently working as a post-doctoral researcher at the University of Illinois at Urbana-Champaign. She is involved with multiple educational research projects with faculty and graduate students at UIUC. Her research interests include diversity and inclusion, teamwork skills, assessment, and identity construction.

\section{Dr. Douglas M. King, University of Illinois, Urbana-Champaign}

Douglas M. King, Ph.D., is a Lecturer in the Department of Industrial and Enterprise Systems Engineering at the University of Illinois at Urbana-Champaign.

\section{Ehsan Salimi, University of Southern California}

Ehsan has obtained his PhD from Industrial and Enterprise Systems Engineering department at University of Illinois at Urbana-Champaign in 2015. He is currently a postdoctoral scholar at Industrial and Systems Engineering at University of Southern California. 


\title{
Using Case Studies to Enhance the Critical Thinking Skills of IE students
}

\begin{abstract}
The most challenging aspects of teaching probability and statistics to engineering students are the theoretical nature of the topic and the disconnection of the material taught with real-world engineering problems. Although the engineering curriculum in most cases has been updated and expanded to incorporate group work and project-based learning, most of the mathematical oriented courses are still taught in a passive manner.
\end{abstract}

Our goal is to enhance students' critical thinking by integrating case studies to our introductory course in probability and statistics. This is typically a sophomore-level core course in the industrial engineering curriculum. Students who complete this course, should be able to understand the role of uncertainty in engineering models, apply critical probability concepts (e.g. independence, expectation, variance), identify and analyze discrete and continuous random variables, and formulate and conduct statistical analyses of observed data.

One key innovation that we implemented is the introduction of real-world data-driven case studies. We wish to expose our students to engineering problems that will help them relate the material taught in class with their own major. The primary enabling technology is statistical programming with Python. The case studies are introduced as group assignments and are motivated in class or discussion sessions. Students select their own groups and in the end of each case study, they do a peer-evaluation in order to assess the degree of in-group collaboration. In this way, students build valuable competencies, such as problem solving, critical thinking, and collaboration. We have also updated the way the students are being evaluated; therefore, case studies are graded based on rubrics that clearly communicate our expectations to the students. Finally, to track the progress and evaluate the success of the above innovations, we have created an attitudes survey (beginning/end of the semester) and an informal early feedback survey (middle of the semester).

Based on the feedback we got from the students, as well as their grades in the case studies and exams, the implemented innovations improved our students' critical thinking and trained them in working in groups. Furthermore, by having them work in realistic case studies, they gained a deeper understanding of statistical concepts, enhanced by the necessary technical foundations in theory and programming.

Introduction

Critical thinking is an important skill for engineering students and is the central theme of our course redesign in one of our core Industrial Engineering (IE) courses. According to philosopher Peter Facione, critical thinking is defined as the intellectually disciplined process of actively and skillfully conceptualizing, applying, analyzing, synthesizing, and/or evaluating information gathered from, or generated by, observation, experience, reflection, reasoning, or communication, as a guide to belief and action ${ }^{[4]}$. In layman's terms, critical thinking is reflectively thinking through and making decisions about a problem using logic and rationale based upon credible evidence. Some researchers argue that critical thinking has three key 
elements: reason, reflection and judgment ${ }^{[14]}$. Also, the upper levels of Bloom's taxonomy are labeled as indicators of critical thinking: analysis, synthesis, and evaluation ${ }^{[3]}$. Critical thinking has been explored in multiple disciplines, including philosophy, psychology, and sociology. The combination of the three distinct disciplines collectively identifies three perspectives or conceptual models to consider critical thinking including skills or ability ${ }^{[10,11]}$, disposition ${ }^{[3,4,6]}$, and developmental ${ }^{[18,19]}$.

Critical thinking has been assessed by a variety of methods including essays, scoring rubrics, and performance measures such as GPA, SAT scores, and portfolios. Effective assessment can expose necessary pedagogical adjustment to enhance student's critical thinking skills ${ }^{[12]}$. Ralston $\&$ Bays developed a rubric to assess critical thinking in the context of engineering courses based upon a social science model of critical thinking ${ }^{[14]}$. Also, educators have specified student's ability to develop critical thinking skills as a fundamental educational objective and an essential component of the general education of college students ${ }^{[15]}$. Schamber and coauthors encourage the use of formative assessment data for instructional innovation and enhancing student learning, including developing critical thinking skills ${ }^{[15]}$.

In this study, our goal is to improve student's critical thinking skills through case-based instruction within a collaborative learning environment. Specifically, this study adds to the engineering education literature by incorporating critical thinking in a core Industrial Engineering (IE) course through team investigations of case studies.

Collaborative learning groups and teamwork are a fundamental building block within engineering education. Teamwork is a common component in most engineering curricula and engineering companies typically use teams as the basic unit of knowledge sharing and sometimes performance. Generally, engineering faculty view teaming skills as valuable to engineering students and collaborative learning provides an opportunity for students to practice professional skills while in college. Additionally, multiple studies have identified teamwork as one of the most valued and necessary skills for college graduates, as the majority of engineering employers want engineering educators to focus on developing students' teaming and collaboration skills ${ }^{[7]}$. Despite the clear emphasis on teamwork in engineering and the increasing use of student team projects, our understanding of how to support engineering students to develop these skills is limited ${ }^{[1]}$. Some engineering education researchers consider how to teach teaming skills in engineering courses ${ }^{[9]}$, but some others question if teamwork can be taught ${ }^{[17]}$. Moreover, few studies have linked student collaborative learning or teaming skills to specific instructional strategies.

Case-based instruction asks students to analyze realistic data of either historical or hypothetical situations and perform a systematic problem-solving procedure using sound technical decisions ${ }^{[13]}$. Previous studies demonstrated the effectiveness of case-based instruction in improving student's problem-solving skills and ability to translate a technical approach into a similar context ${ }^{[8]}$. More importantly, case-based instruction is a fairly popular active learning instructional strategy that is familiar to many engineering faculty ${ }^{[5]}$.

In light of the engineering faculty being at least aware of case-based instruction, we saw it as a viable option to redesign a core IE course in order to incorporate critical thinking by asking 
students to investigate, in teams, real-world, data-driven examples. The fundamental research question in this redesign was the following: do case-based instructional strategies provide an effective method to improve IE students' critical thinking skills? Building on successful assessments of critical thinking in previous research, we developed an internal assessment measurement that reflects our local context. Moreover, since our instructional strategy was to combine case studies with collaborative learning, we also developed instruments to evaluate student perceptions of their team experience.

Targeted course: First course in probability and statistics

The course considered in this study is an introductory course in probability and statistics for engineering students with a background in multivariate calculus. The probability component of the course begins with basic combinatorics and the axioms of probability, and ends with analysis and applications of univariate and multivariate distributions of discrete and continuous random variables. The statistics component of the course covers simple numerical and visual descriptions of data, interval estimation, hypothesis testing, and linear regression. The goal of this course is to provide engineering students with a comprehensive survey of probability and statistics.

Specifically, our IE students traditionally take this course in their fourth semester. Moreover, it is a required course for other engineering disciplines including Aerospace Engineering, Chemical Engineering, and Materials Science and Engineering curricula, and satisfies a statistics requirement in the Agricultural Engineering and Mechanical Engineering curricula. Hence, the variety of technical background of the students taking the course leads to wide range of expectations of the course by students. Furthermore, this IE course will be the only direct exposure to probability in some students' coursework, while others will rely on it to prepare them for more advanced coursework on these topics (e.g., design of experiments, simulation, stochastic processes). Hence, it must serve both as a terminal course that prepares students for their careers after graduation, as well as an introductory course that provides a foundation for future academic study including related sequenced courses in other engineering departments.

Students enrolled in this course typically have four contact hours each week: three hours of lecture led by an instructor and one hour of lab led by a teaching assistant. Through the 20142015 academic year, course assessments consisted of homework assignments, in-class quizzes, midterm exams, and a comprehensive final exam. Quizzes were typically unannounced, and were held in both lecture and lab meetings. Lectures applied the traditional teaching approach of direct instruction, with the instructor presenting course materials to the class. However, all lab meetings were held in a recitation format, with the teaching assistant answering student questions and presenting prepared examples to demonstrate the application of course materials. Thus, the goal of the labs was to reinforce the concepts introduced during lecture, rather than to introduce new topics.

In the end of the Spring 2015 semester, we surveyed the students enrolled in the course, in order to evaluate their familiarity with programming as well as their attitude towards the integration of a programming component and the introduction of team-based projects in the course. The "informal" or formative assessment indicated that the vast majority of the students had little to no exposure to programming in their previous engineering courses. However, only half of them 
considered the introduction of programming into the course necessary. The results are summarized in Table 1.

\begin{tabular}{|c|c|c|c|}
\hline \multicolumn{4}{|c|}{ Students' programming experience } \\
\hline None & Limited & Moderate & Strong \\
\hline $16 \%$ & $57 \%$ & $23 \%$ & $4 \%$ \\
\hline \multicolumn{4}{|c|}{ Students' programming skills } \\
\hline Matlab & $R$ & $\mathrm{C} / \mathrm{C}++$ & Other \\
\hline $24 \%$ & $21 \%$ & $8 \%$ & $47 \%$ \\
\hline \multicolumn{4}{|c|}{ Students' experience working in projects } \\
\hline $0-1$ projects & $2-3$ & $4-5$ & $>6$ \\
\hline $38 \%$ & $41 \%$ & $18 \%$ & $3 \%$ \\
\hline
\end{tabular}

Table 1: Students' Background in Spring 2015

Although the students' preference on adding new components to the course was divided, we decided to integrate computational material in the course as part of the course re-design. Our hope is that this will enhance students' self-directed learning and specifically, their critical thinking skills. Our over-arching objective was to strengthen the skillset of our graduates to effectively prepare them for the job market or if they continue to graduate studies.

There is a variety of statistical and mathematical software as well as programming languages that can be employed. In the statistical education literature, there is consensus that integrating software programming in statistics and probability courses is imperative ${ }^{[20]}$. However, the specific methodology to incorporate programming into a statistics course depends on the students' major and their level of prior exposure and engagement with programming software. We chose to integrate Python, as it is a powerful programming language and an industry standard that has capabilities of analyzing large datasets consistent with professional IE work.

As it was mentioned before, the targeted course serves other engineering departments in our university. Therefore, the students that are registered in this course are a mixture of industrial, general, material science, mechanical, and aerospace engineers as it is shown in Figure 1. Although the majority of students are in their junior year, a little bit less than half of the class consists of sophomore and senior students (Figure 1). 
Majors (Fall 2015)

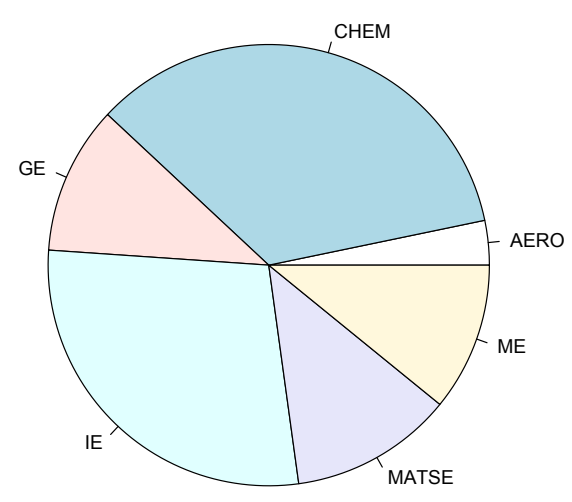

Year in College (Fall 2015)

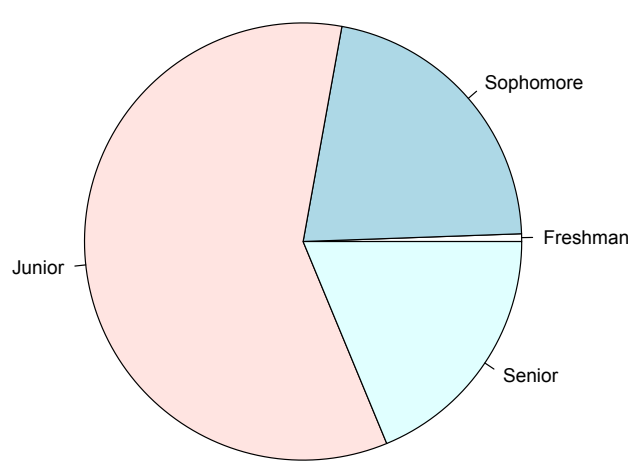

Figure 1: Demographic Breakdown of Student Characteristics Fall 2015

It is interesting to point out that although the majority of the students are in their junior year, only $21 \%$ had experienced more than three collaborative project-based learning activities over the course of their engineering education (Table 1). As a result, we decided that it is necessary to train our students to work in a collaborative team environment.

Case studies development

One of our main objectives in this study is to bridge the gap between the material taught in class and real life problems; our goal is that students develop the ability to relate and apply theoretical concepts to real-world applications, in addition to fully understanding these concepts. To achieve this goal, we introduced two real-world, data-driven case studies to our introductory course in probability and statistics.

The first case study is dedicated to the problem of finding the fastest flight for certain airplane routes. The airline data used in this case is publicly available and can be found on the fivethirtyeight.com website ${ }^{[16]}$. This case study is divided in two parts: the first one is designed so that student can familiarize themselves with Python programming software and perform a simple data analysis task. In particular, the main goal is to guide the students in writing and reading data from files and performing basic data manipulations, such as cleaning a data set, calculating the number of observations and computing averages of subsets of data. To demonstrate their ability to perform these skills, we asked the students to compute the flight time for a specific route and a specific airline, the targeted flight time, i.e. an estimate of how long a specific flight should take based on distance and direction of travel.

The second part of the first case study required more rigorous analysis, such as the computation of conditional probabilities as well as development of a very simple classifier that would predict the likelihood of a delay in any given flight. The theoretical concepts for conditional probability 
and Bayes' theorem were covered in class. However, the students were guided on how to develop a classifier based on simple conditional probabilities.

The second case study that was developed introduced the importance of statistics in the global financial market by introducing the students to the reinsurance market. On the theoretical side of the case study, students delved into the "central limit theorem", which is a key concept in the course. The students are expected to visualize the central limit theorem for the given data. This also motivates them to explore graphical tools in Python in order to produce various plots from the data, such as Q-Q plots. In addition, students got to practice with cumulative distribution functions and understand the concept more in depth. The case study was designed such that students were required to revisit the majority of the probabilistic concepts (e.g. conditional probability, integration technique) and apply them at the same time in a different, realistic context. This case study also went one step further, and the students were introduced with heavytailed distributions. It also gave them a motivation to think of realistic scenarios where the bellshaped curve is no longer applicable. Therefore, the students were required to distinguish between heavy-tailed with common light-tailed distributions based upon material presented during class lecture. At the end students were required to use point estimation for a real-life example with provided data and articulate the intuition and logic supporting the decision-making and interpretation of the problem context.

As we discussed before, the case studies were developed as group assignments and therefore students were required to work in cooperative teams and work with other students in their course lecture and discussion sessions. The students were urged to take initiatives, and the instructor or TA played the role of a "facilitator" in the learning process. Since the students had limited experience in teamwork, we decided to let them select their own groups. They were also allowed to switch groups between the different case studies, but not during a case study analysis. At the end of each case study, we conducted a student peer-evaluation in order to assess the degree of in-group collaboration and we shared the results with the students. However, based on the newness of the new course requirements, the degree of collaboration did not count towards their case studies grade for the first semester of the course redesign.

Assessment of case studies

The team decided to assess the student learning outcomes from the second case study using grading rubrics. The rubrics assessed each student's achievement in four possible levels: Not Acceptable (0), Basic/ Minimum (1), Acceptable (2) and Exemplary (3).

To be more specific, the grading rubric for the "reinsurance" case study, was developed based on the following 9 learning objectives:

1. Visualize the concepts in central limit theorem. (C1)

2. Identify cases where classical central limit theorem does not apply. (C2)

3. Reinforce the concept of cumulative distribution function. (C3)

4. Understand why and how QQ-plot works for the assessment of goodness-of-fit. (C4)

5. Reinforce the concepts of conditional probability and conditional expectation. (C5)

6. Apply basic integration technique to compute mean excess function. (C6)

7. Learn about behaviors of a heavy-tailed distribution; (C7) 
8. Learn how to use order statistics to estimate quantiles and mean excess function. (C8) (Demonstrate and apply order statistic for estimation)

9. Develop intuition behind point estimators. (C9) (Comprehend the problem statement and identify appropriate assumptions)

The grading rubric (attached in the appendix) was designed to assess each of these 9 learning objectives in the above four possible categories. The distribution of the students' grades (in percentages) for both case studies is summarized in the following graphs:
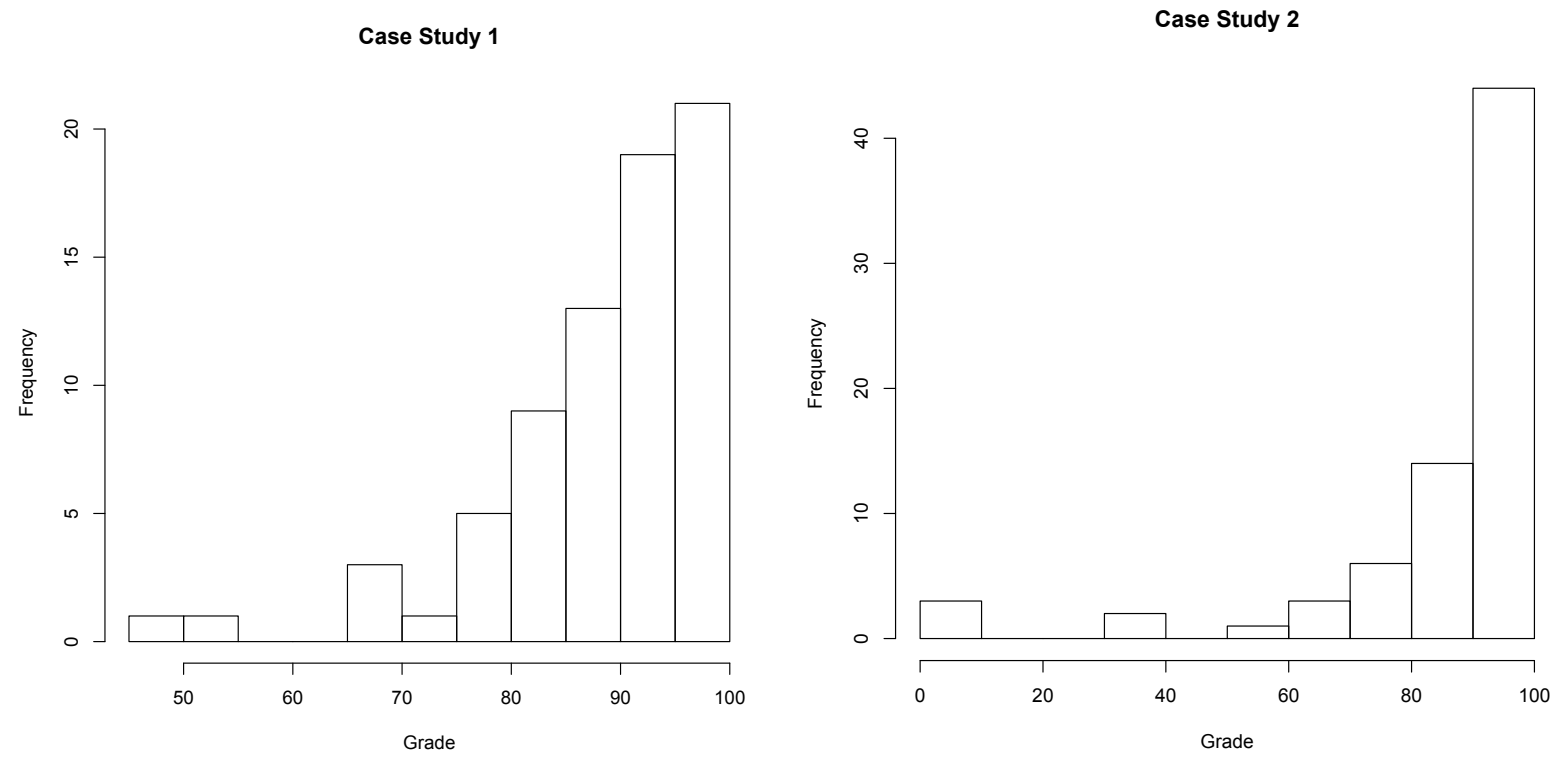

Figure 2: Histogram of case study grades.

From what we observe, both grade distributions were left-skewed, with a little bit less than half of the class getting a grade more than $90 \%$. This means implies that in assessing all 9 learning outcomes, the work was evaluated as 'Exemplary' in at least half of the outcomes. Of course, there are a few instances where the students underperformed or did not complete the case study at all (e.g., zeros in the second case study).

In order to assess the groups' effectiveness we handed out a peer-evaluation to the students. We asked the students how many hours per week they individually worked on the case study; compared to the time they spent working with their peers. We also asked them their perception on how the group performed and we had them give us specific examples on what they learned from the team and what they brought to the team. The goal of the peer-reviews was to be informative and help the students reflect on their individual and group performance. The peer feedback is also very important, as previous research has shown that student's perception of their team function can be very different than the faculty member's perspective of the student team functionality ${ }^{[2]}$.

In general, many groups felt that their teams worked effectively on the case studies, with students often citing group members with prior coding experience (e.g., in Python) as helping the other team members learn how to develop their own code. Students also mentioned the need to 
start meeting with their group members earlier and suggested to meet more frequently in the future. They also discussed the need for each group member to also work separately to understand the case studies before coming together as a team. The students' critical examination of how they worked with their teammates align strongly with our desire to increase the students' abilities to effectively collaborate and team with their group members.

One major concern we had when designing the case studies was the amount of work that they would entail. In order to compensate for the new components added in the course, we decided to drop the lab quizzes and utilize the weekly labs to facilitate the group collaboration and assist the students towards the completion of the case studies. In our end-of-semester survey, we also found that some students did consider the workload significantly higher, but only about $10 \%$ more compared to the previous semester (Spring 2015).

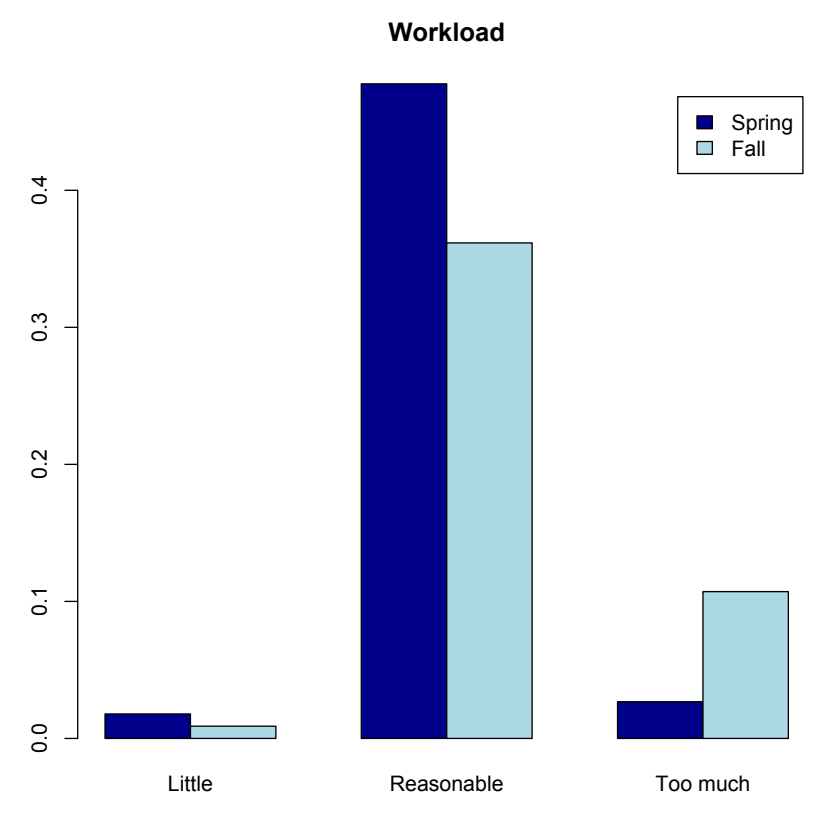

Figure 3: Bar plot of course workload for Spring 2015 vs. Fall 2015.

Although it is not a measure of whether the critical thinking skills of the students were improved, we compared the exam average scores of the students in three consecutive semesters (Fall 2015, Spring 2015, Fall 2014) for the same instructor. It turns out that the final exam scores were lower in Fall 2015 compared to the two previous semesters. However, both midterm exams as well as homework grades showed no statistically significant difference. The lower observed final exam scores could be attributed to several factors. First, in addition to introducing case studies and computational material, we also decided to increase the scope of the materials typically covered in the course. For example, linear regression was added, as well as more content on hypothesis testing - which are both topics covered in the end of the semester and hence would not have appeared on the midterm examinations. Moreover, because we devoted the labs sessions to the case studies, there was less in-class reinforcement of the course material. The combination of these structural changes provides a plausible explanation for the drop in performance. 
Reflecting upon the implementation of the case studies and the results, the main difficulty we observed was the students' unfamiliarity with programming and specifically with Python. This issue delayed full involvement in the case studies' theoretical part and as a result some students were only focused on improving their programming skills, which is a positive point itself, however not in the scope of this class. In order to overcome this difficulty, we have initiated a curriculum change to require a Python-based programming class before taking is course.

\section{Teaching assistants (TAs)}

Since the targeted course has typically very high enrollment (approximately 300-400 students per semester), there are several course TAs that lead the lab sections. In addition to these, we also had two full-time teaching assistants bridging the gap between the TAs and the course instructors. In particular, a beginning-of-semester training workshop for the TAs included a Python tutorial, as well as several sessions during the semester that discussed the details and learning objectives of each case study. Moreover, in order to further assist the students in their new tasks, weekly office hours were devoted to Python and case study related questions.

The course TAs, as it was mentioned before, held more of a leading role in the lab sessions, guiding the students through the investigation of the case studies. However, based on our experience from the Fall 2015 semester, we overlooked the fact that leading a group based recitation session requires more advanced teaching skills than a more traditional recitation format of solving problems on the blackboard, or answering questions. As a result, we faced some challenges in the way the labs were held, as well as the helpfulness of the TAs to the students. This was also depicted in the end-of-semester survey from the students' comments.

In order to remedy this situation, this semester we are holding weekly TA meetings with the instructors and the computational TAs. Our goal is to have the teaching assistants take the role of the student and let them work in groups in order to complete the weekly tasks. Therefore, we hope that by guiding them do collaborative work, this will improve their teaching skills and will support them in leading a group-based lab.

\section{Faculty outcomes}

Apart from the student learning outcomes, we as instructors gained valuable experience during the development of the case studies and the new material for the course including adopting novel assessment strategies. Beginning in the Spring 2015 semester, we had weekly meetings where we decided what kind of innovations we should introduce in this course. All innovations were decided and developed in a collaborative environment, where a group of faculty members, lecturers, engineering education researchers and graduate students participated. All the developed materials are very well documented and will be shared with new faculty members teaching this course and joining the group, in order to guarantee continuous improvement and sustainability of the changes we made. Overall, this whole process strengthened the sense of community in the department and created an environment of support and collaboration while engaging in implementing instructional innovation to improve our student outcomes including critical thinking. 


\section{Conclusion}

To summarize our goal in this project was to use team-based case studies and computational material in order to improve students' critical thinking skills. Training the students to learn how to work in a group setup was one of our main goals. Since most of the students had limited exposure to group-based learning projects, peer feedback and evaluation was a key element to the success of the student teams. Peer feedback showed that student starting feeling more comfortable working in a group setup over time.

However, the lack of effective TA support to the students created a disconnection of the material presented in the lecture with these taught in the lab, which is currently addressed by proper TA training. Our main change this semester is the initiation of weekly TA meetings, in order to train the TAs on how to reinforce the core concepts of the case studies while linking them to the material taught in class.

An unanticipated outcome of this process was the faculty learning. Not only did we have a positive experience working in a group, revamping one of the largest courses in our department, we also gained valuable experience and energy to implement instructional innovations to other core courses.

While this study represents an excellent first iteration in refining this course, clear areas for improvement still exist. The faculty team is continuing to revise the course to both achieve the stated goal of improving students' critical thinking skills and better prepare the enrolled students for their future coursework and post-graduation careers. Hence, there is a continuous process improvement component to the work presented here.

While this study has produced several illuminating insights into the nature of our course and its students, the results presented in this paper are limited in several ways. First, the analysis presented here only considers data measuring outcomes for one semester's offering of the course. Moreover, it must be emphasized that this research was conducted at a single institution, which limits the ability to generalize our results to other institutions. As we continue to refine the course, data gathered over a longer horizon will give greater insight into the impact of these evolving changes on our students. 


\begin{tabular}{|c|c|c|c|c|}
\hline $\begin{array}{l}\text { Learning } \\
\text { Objective }\end{array}$ & $\begin{array}{c}\text { Level 0 } \\
\text { (Not Acceptable) }\end{array}$ & $\begin{array}{c}\text { Level } 1 \\
\text { (Basic/Minimum) }\end{array}$ & $\begin{array}{c}\text { Level } 2 \\
\text { (Acceptable) }\end{array}$ & $\begin{array}{c}\text { Level } 3 \\
\text { (Exemplary) }\end{array}$ \\
\hline $\mathrm{C} 1$ & $\begin{array}{l}\text { Not understanding } \\
\text { central limit theorem } \\
\text { (no trace from CLT in } \\
\text { any argument or } \\
\text { formula) }\end{array}$ & $\begin{array}{l}\text { Knowing the concept } \\
\text { but unable to visualize } \\
\text { (fully understanding } \\
\text { the concept but unable } \\
\text { to provide the visual } \\
\text { diagram) }\end{array}$ & $\begin{array}{l}\text { Fully understanding the } \\
\text { concept but the final } \\
\text { parameters for the CLT are } \\
\text { not fully correct }\end{array}$ & $\begin{array}{l}\text { Fully understanding the } \\
\text { concept and the final } \\
\text { parameters for CLT are } \\
\text { correct }\end{array}$ \\
\hline $\mathrm{C} 2$ & $\begin{array}{l}\text { Not understanding } \\
\text { central limit theorem } \\
\text { (cannot write equation) }\end{array}$ & $\begin{array}{l}\text { Applying CLT without } \\
\text { correct assumptions } \\
\text { (can write equation) }\end{array}$ & $\begin{array}{l}\text { Understanding the } \\
\text { assumption but making } \\
\text { small mathematical } \\
\text { mistakes (or calc error) }\end{array}$ & $\begin{array}{l}\text { Fully understanding the } \\
\text { assumptions and using } \\
\text { correctly; indicate when } \\
\text { not to use theorem }\end{array}$ \\
\hline C3 & $\begin{array}{l}\text { Not understanding and } \\
\text { using CDF (cannot } \\
\text { write the mathematical } \\
\text { definition) }\end{array}$ & $\begin{array}{l}\text { Using CDF not } \\
\text { correctly (can write } \\
\text { equation) }\end{array}$ & $\begin{array}{l}\text { Using CDF correctly with } \\
\text { minor mistakes (wrong } \\
\text { bounds or mistakes in } \\
\text { computing at some } \\
\text { intervals) }\end{array}$ & $\begin{array}{l}\text { Using CDF correctly } \\
\text { with correct values. }\end{array}$ \\
\hline $\mathrm{C} 4$ & $\begin{array}{l}\text { Not understanding the } \\
\text { idea of QQ-plot (not } \\
\text { using it) }\end{array}$ & $\begin{array}{l}\text { Using the QQ-plot but } \\
\text { unable to realize the } \\
\text { connection to the } \\
\text { concept of goodness- } \\
\text { of-fit }\end{array}$ & $\begin{array}{l}\text { Understanding the } \\
\text { connection of the QQ-plot } \\
\text { to goodness-of-fit } \\
\text { assessment } \\
\text { Minor mistakes in } \\
\text { assessment of } \\
\text { determination or decision }\end{array}$ & $\begin{array}{l}\text { Using QQ-plot with the } \\
\text { correct assessment of } \\
\text { goodness-of-fit }\end{array}$ \\
\hline $\mathrm{C} 5$ & $\begin{array}{l}\text { Not understanding the } \\
\text { concept of conditional } \\
\text { probability or } \\
\text { conditional expectation } \\
\text { or even expectation }\end{array}$ & $\begin{array}{l}\text { Not understanding the } \\
\text { concept of conditional } \\
\text { probability and } \\
\text { misunderstood the } \\
\text { conditional expectation }\end{array}$ & $\begin{array}{l}\text { Understanding fully the } \\
\text { concept of conditional } \\
\text { expectation and using it } \\
\text { Minor errors in } \\
\text { computation or computing }\end{array}$ & $\begin{array}{l}\text { Understanding the } \\
\text { conditional expectation } \\
\text { fully and using it } \\
\text { correctly } \\
\text { Final result is correct }\end{array}$ \\
\hline
\end{tabular}




\begin{tabular}{|c|c|c|c|c|}
\hline & & $\begin{array}{l}\text { Mistake in the } \\
\text { conditioned set }\end{array}$ & the constrained set & \\
\hline C6 & $\begin{array}{l}\text { Not applying basic } \\
\text { integration techniques }\end{array}$ & $\begin{array}{l}\text { Using the integration } \\
\text { technique } \\
\text { Using incorrect } \\
\text { boundary conditions } \\
\text { Totally incorrect final } \\
\text { result }\end{array}$ & $\begin{array}{l}\text { Using the integration } \\
\text { technique with correct } \\
\text { bounds } \\
\text { Minor error in the process } \\
\text { of computing the } \\
\text { integration }\end{array}$ & $\begin{array}{l}\text { Applying the integration } \\
\text { technique fully correct }\end{array}$ \\
\hline $\mathrm{C} 7$ & $\begin{array}{l}\text { Not understanding the } \\
\text { heavy-tailed } \\
\text { distribution }\end{array}$ & $\begin{array}{l}\text { Unable to realize } \\
\text { (identify, explain, or } \\
\text { address) the effect of } \\
\text { heavy-tailed } \\
\text { distribution on the } \\
\text { average. } \\
\text { Not using the Pareto } \\
\text { distribution correctly }\end{array}$ & $\begin{array}{l}\text { Understanding the effect of } \\
\text { heavy-tailed distribution on } \\
\text { average } \\
\text { Able to make arguments } \\
\text { about the heavy-tailed } \\
\text { distribution but with some } \\
\text { mistakes }\end{array}$ & $\begin{array}{l}\text { Fully understanding the } \\
\text { heavy- tailed distribution } \\
\text { Able to draw correct } \\
\text { result in the case of } \\
\text { heavy-tailed distribution }\end{array}$ \\
\hline $\mathrm{C} 8$ & $\begin{array}{l}\text { Not understanding the } \\
\text { concept of order } \\
\text { statistics (Unable to } \\
\text { demonstrate the } \\
\text { importance or apply } \\
\text { order statistic for } \\
\text { estimation) }\end{array}$ & $\begin{array}{l}\text { Able to apply the order } \\
\text { statistics in estimating } \\
\text { quantiles and mean } \\
\text { excess function } \\
\text { Mistakes in the } \\
\text { procedure which results } \\
\text { in a complete wrong } \\
\text { solution }\end{array}$ & $\begin{array}{l}\text { Using the order statistics to } \\
\text { estimate the desired } \\
\text { parameters with the correct } \\
\text { procedure with minor } \\
\text { errors }\end{array}$ & $\begin{array}{l}\text { Fully understanding the } \\
\text { order statistics and its } \\
\text { role in the estimation } \\
\text { Correct procedure and } \\
\text { correct result }\end{array}$ \\
\hline C9 & $\begin{array}{l}\text { Not understanding the } \\
\text { concept of estimation } \\
\text { and point estimation }\end{array}$ & $\begin{array}{l}\text { Understand the concept } \\
\text { of estimation without } \\
\text { fully able to apply it. } \\
\text { (Describing when and } \\
\text { why estimation and } \\
\text { what kind is } \\
\text { appropriate) }\end{array}$ & $\begin{array}{l}\text { Understanding the intuition } \\
\text { behind the point estimation } \\
\text { and the procedure to } \\
\text { compute it (Identifying the } \\
\text { correct assumptions) } \\
\text { - Minor errors in the } \\
\text { procedure resulting in } \\
\text { wrong estimator }\end{array}$ & $\begin{array}{l}\text { Full intuition behind } \\
\text { point estimators and the } \\
\text { computing procedure } \\
\text { with a correct final result }\end{array}$ \\
\hline
\end{tabular}


References

1. Borrego, M., Karlin, J., McNair, L. D., \& Beddoes, K. (2013). Team Effectiveness Theory from Industrial and Organizational Psychology Applied to Engineering Student Project Teams: A Research Review. Journal of Engineering Education, 102(4), 472-512.

2. Chapman, K. J., Meuter, M. L. Toy, D., \& Wright, L. K. (2010). Are Student Groups Dysfunctional? Perspectives From Both Sides of the Classroom. Journal of Marketing Education, 32(1), 39-49.

3. Ennis, R. H. (1993). Critical thinking assessment. Theory into practice, 32(3), 179-186.

4. Facione, P. A., Sánchez, C. A., Facione, N. C., \& Gainen, J. (1995). The disposition toward critical thinking. The Journal of General Education, 1-25.

5. Froyd, J. E., Borrego, M., Cutler, S., Henderson, C., \& Prince, M. J. (2013). Estimates of use of researchbased instructional strategies in core electrical or computer engineering courses. IEEE Transactions on Education, 56(4), 393-399. doi:10.1109/TE.2013.2244602

6. Halpern, D. F. (1999). Teaching for critical thinking: Helping college students develop the skills and dispositions of a critical thinker. New directions for teaching and learning, 1999(80), 69-74.

7. Hughes, R. L., \& Jones, S. K. (2011). Developing and assessing college student teamwork skills. New Directions for Institutional Research, 2011(149), 53-64.

8. Jonassen, D. H., \& Hernandez-Serrano, J. (2002). Case-Based Reasoning and Instructional Design: Using Stories To Support Problem Solving. Educational Technology Research and Development, 50(2), 65-77.

Retrieved from http://search.ebscohost.com/login.aspx?direct=true\&db=eric\&AN=EJ652498\&site=ehostlive

9. Matusovich, H. M., Paretti, M. C., Motto, A., \& Cross, K. (2012). Understanding Faculty and Student Beliefs about Teamwork \& Communication Skills. Proceedings- American Society for Engineering Education Annual Conference and Exposition, San Antonio, TX.

10. Nosich, G. M. (2005). Problems with Two Standard Models for Teaching Critical Thinking. New Directions for Community Colleges(130), 59-67. Retrieved from http://dx.doi.org/10.1002/cc.196

11. Paul, R., \& Nosich, G. M. (1992). A Model for the National Assessment of Higher Order Thinking. Retrieved from http://www.criticalthinking.org/pages/a-model-for-the-national-assessment-of-higher-orderthinking/591

12. Peach, B. E., Mukherjee, A., \& Hornyak, M. (2007). Assessing critical thinking: A college's journey and lessons learned. Journal of Education for Business, 82(6), 313-320.

13. Prince, M. J., \& Felder, R. M. (2006). Inductive teaching and learning methods: Definitions, comparisons, and research bases. Journal of Engineering Education-Washington-, 95(2).

14. Ralston, P., \& Bays, C. (2010). Refining a critical thinking rubric for engineering. 2010 Annual Conference \& Exposition, Louisville, Kentucky. https://peer.asee.org/16577.

15. Schamber, J. F., \& Mahoney, S. L. (2006). Assessing and improving the quality of group critical thinking exhibited in the final projects of collaborative learning groups. The Journal of General Education, 55(2), 103-137.

16. Silver, N. (2015). We found the fastest flights, Retrieve from http://fivethirtyeight.com/features/how-wefound-the-fastest-flights/

17. Shuman, L. J., Besterfield-Sacre, M., \& McGourty, J. (2005). The ABET "Professional Skills" — Can They Be Taught? Can They Be Assessed? Journal of Engineering Education, 94(1), 41-55. Retrieved from http://ezproxy.lib.vt.edu:8080/login?url=http://search.ebscohost.com/login.aspx?direct=true\&db=a9h\&AN $=16164285 \&$ scope $=$ site

18. Stupnisky, R., Renaud, R., Daniels, L., Haynes, T., \& Perry, R. (2008). The Interrelation of First-Year College Students' Critical Thinking Disposition, Perceived Academic Control, and Academic Achievement. Research in Higher Education, 49(6), 513-530. doi:10.1007/s11162-008-9093-8

19. Szenes, E., Tilakaratna, N., \& Maton, K. (2015). The knowledge practices of 'critical thinking'. Critical Thinking in Higher Education. London: Palgrave Macmillan.

20. Tishkovskaya, S., \& Lancaster, G. (2012). Statistical education in the 21st century: a review of challenges, teaching innovations and strategies for reform. Journal of statistics education, 20 (2). 